\title{
Functional properties of platelets in piglets when changing methods of nutrition
}

\author{
Svetlana $Y u$. Zavalishina* \\ Russian State Social University, Moscow 129226, Russia
}

\begin{abstract}
A functionally significant element in ensuring homeostasis of the internal environment of an animal organism is platelets. The state of their activity greatly influences the rheology of blood in small vessels and, thus, the metabolism in tissues. It becomes clear that the process of growth and development of piglets at any age substantially depends on the level of their activity. In this regard, the assessment of agerelated changes in platelet activity in piglets during their early ontogenesis is of great importance. In the work performed, it was found that in piglets during the dairy and vegetable nutrition phase there is an increase in the adhesive, aggregation and secretory properties of platelets. The leading cause of these changes can be the enhancement of receptor processes and activation of the work of post-receptor mechanisms of information transfer in platelets. This is noted in piglets during the milk-plant nutrition phase simultaneously for both strong and weak aggregation inducers. The growth of platelet activity in piglets found during the observation period apparently was due to the intensification of thromboxane generation in platelets as a result of the increased activity of their cyclooxygenase and thromboxane synthetase, as well as an increase in the secretion of ADP molecules from them. The increase in the severity of the hemostatic properties of platelets in piglets during the milk-plant nutrition phase seems to be a serious regulator of their microcirculation and metabolism processes in any environmental conditions.
\end{abstract}

\section{Introduction}

Being the main fluid medium of the whole organism, blood continuously maintains its vitality and the necessary level of adaptation to any environmental conditions [1]. Its enormous biological significance is associated with continuous movement and maintaining the vitality of the animal's body by delivering the right amount of oxygen and necessary substances to all parts of the body and removing unnecessary metabolites $[2,3]$. These processes take place in the lumen of the capillary bed, and in this regard, the success of blood flow in it is very biologically significant [4]. The intensity of metabolism, growth and the overall viability of animals strongly depend on the course of microcirculation processes [5].

These processes are important for all productive animals [6]. The degree of development of all their productive indicators, which means the success of their breeding and cultivation, depends on their intensity [7].

In pigs and pigs, aspects of blood physiology are only beginning to be studied in detail. As before, not all moments of microcirculation in growing pigs can be considered clarified [8]. In earlier studies, much attention was paid to the rheological indices of red blood cells, which are the most numerous group of blood cell forms. They managed to find out the presence of their changes with increasing age and the possibility of a violation in response to various environmental factors. At the same time, the functional abilities of the blood platelets, which play a large role in the microcirculation processes, were given little attention to the piglets.

In the work performed on a person, a high functional role of platelets in ensuring the vital processes and work of hemostasis has been repeatedly noted [9]. This is because platelets are recognized as the initiating link in the functioning of hemostasis and participants in all mechanisms of hemostatic reactions [10]. However, in the body of pigs, many aspects of platelet activity require clarification. This is of great relevance in piglets in the third phase of their early ontogenesis. The study of aspects of platelet activity in piglets of dairy and vegetable nutrition will allow stimulating the development of effective options for the intensification of the processes of growth and development of animals.

In the work performed, the goal was set: to establish the physiological dynamics of the physiological properties of platelets in piglets during the milk-plant nutrition phase.

\section{Materials and methods}

The research was conducted in strict accordance with ethical principles established by the European Convent on protection of the vertebrata used for experimental and other scientific purposes (adopted in Strasbourg in March 18, 1986, and confirmed in Strasbourg in June 15, 2006).

* Corresponding author: svetlanazsyu@ mail.ru 
This work was carried out on 37 completely healthy piglets belonging to the large white breed taken under observation at 21 days of age. All animals were obtained from sows of optimal physiological status by 2-3 litters. All animals in the study were examined 5 times: at the age of 21 days, 25 days, 30 days, 35 days and 40 days of their life.

The activity of platelet aggregation (AP) was determined in piglets using a visual micro-method in response to thrombin ( 0.125 units $/ \mathrm{ml}$ ), on ADP (dose $\left.0.5 \times 10^{-4} \mathrm{M}\right)$, on $\mathrm{H}_{2} \mathrm{O}_{2}\left(\right.$ dose $\left.7.3 \times 10^{-3} \mathrm{M}\right)$, for collagen (dose 1: 2 of the main suspension), for ristomycin (dose $0.8 \mathrm{mg} / \mathrm{ml}$ ), for adrenaline (dose $5.0 \times 10^{-6} \mathrm{M}$ ). This was carried out in the plasma of animals, which had previously been standardized on the level of the platelets contained in it to the value of $200 \times 10^{9}$ platelets per liter. The state of intravascular platelet aggregation ability was performed using phase contrast.

Mediated in the platelets of the examined piglets, the intensity level of thromboxane synthesis was detected and the enzymatic properties of its platelet generation enzymes, cyclooxygenase and thromboxane synthetase, were determined. This was achieved by determining the level of AP in the course of three transfer tests carried out on a photoelectric colorimeter. At the same time, in the platelets of the observed piglets, the available amount of ADP and the level of its secretion were recorded as a result of exposure to thrombin on the platelets.

All digital results obtained in the work were processed using Student's criterion.

\section{Results}

In the piglets at the stage of milk and vegetable nutrition, a gradual increase in the activity of thromboxane formation in their platelets was revealed. This was indicated by an increase in the level of AP during a simple transfer test (from the level of $41.4 \pm 0.06 \%$ to a value of $48.8 \pm 0.07 \%$ ). This was based on the activation of thromboxane synthetase and cyclooxygenase in the blood plates of piglets.

Table 1. Platelet counts in piglets when changing methods of feeding

\begin{tabular}{|c|c|c|c|c|c|}
\hline \multirow{2}{*}{ Considered hemostatic parameters } & \multicolumn{5}{|c|}{ The term ontogeny of piglets, $n=37, M \pm m$} \\
\hline & $\begin{array}{l}21 \text { day of } \\
\text { life }\end{array}$ & $\begin{array}{l}25 \text { day of } \\
\text { life }\end{array}$ & 30 day of life & 35 day of life & 40 day of life \\
\hline $\begin{array}{l}\text { The severity of the recovery of platelet } \\
\text { aggregation in the collagen-aspirin test, } \%\end{array}$ & $75.0 \pm 0.08$ & $75.7 \pm 0.09$ & $76.3 \pm 0.06$ & $77.7 \pm 0.09$ & $\begin{array}{l}78.7 \pm 0.12 \\
\mathrm{p}<0.05\end{array}$ \\
\hline $\begin{array}{l}\text { The severity of the recovery of platelet } \\
\text { aggregation in the collagen-imidazole } \\
\text { sample, } \%\end{array}$ & $64.2 \pm 0.07$ & $64.9 \pm 0.05$ & $65.5 \pm 0.04$ & $66.7 \pm 0.08$ & $\begin{array}{c}69.6 \pm 0.09 \\
\mathrm{p}<0.05\end{array}$ \\
\hline $\begin{array}{l}\text { The level of platelet aggregation in a simple } \\
\text { transfer test, \% }\end{array}$ & $41.4 \pm 0.06$ & $42.6 \pm 0.09$ & $43.8 \pm 0.10$ & $45.2 \pm 0.09$ & $\begin{array}{l}48.8 \pm 0.07 \\
\mathrm{p}<0.05\end{array}$ \\
\hline $\begin{array}{l}\text { The content of ADP in platelet granules, } \\
\text { mmol } / 10^{9} \text { platelets }\end{array}$ & $3.36 \pm 0.07$ & $3.39 \pm 0.06$ & $3.48 \pm 0.05$ & $3.61 \pm 0.10$ & $3.78 \pm 0.09$ \\
\hline $\begin{array}{l}\text { The severity of secretion of ADP from } \\
\text { platelets during their stimulation, } \%\end{array}$ & $40.4 \pm 0.10$ & $41.5 \pm 0.09$ & $42.8 \pm 0.09$ & $44.2 \pm 0.07$ & $46.1 \pm 0.12$ \\
\hline Platelet aggregation time with ADP, s & $39.4 \pm 0.10$ & $38.5 \pm 0.08$ & $37.4 \pm 0.05$ & $36.7 \pm 0.09$ & $\begin{array}{c}34.2 \pm 0.10 \\
\mathrm{p}<0.05\end{array}$ \\
\hline Platelet aggregation time with collagen, $\mathrm{s}$ & $29.0 \pm 0.08$ & $28.4 \pm 0.05$ & $27.7 \pm 0.06$ & $26.6 \pm 0.08$ & $\begin{array}{l}24.5 \pm 0.05 \\
\mathrm{p}<0.05\end{array}$ \\
\hline Platelet aggregation time with thrombin,s & $41.0 \pm 0.07$ & $40.1 \pm 0.06$ & $39.2 \pm 0.09$ & $38.1 \pm 0,03$ & $\begin{array}{c}36.0 \pm 0,07 \\
\mathrm{p}<0.05\end{array}$ \\
\hline Platelet aggregation time with $\mathrm{H}_{2} \mathrm{O}_{2}, \mathrm{~s}$ & $40.7 \pm 0.07$ & $40.0 \pm 0.07$ & $39.1 \pm 0.09$ & $38.2 \pm 0.10$ & $\begin{array}{l}37.0 \pm 0.06 \\
\mathrm{p}<0.05\end{array}$ \\
\hline Platelet aggregation time with ristomycin, $\mathrm{s}$ & $40.0 \pm 0.06$ & $39.0 \pm 0.08$ & $37.5 \pm 0.09$ & $36.2 \pm 0.10$ & $\begin{array}{c}35.3 \pm 0.12 \\
\mathrm{p}<0.05\end{array}$ \\
\hline Platelet aggregation time with adrenaline, $\mathrm{s}$ & $93.1 \pm 0.08$ & $92.0 \pm 0.14$ & $90.6 \pm 0.09$ & $88.5 \pm 0.11$ & $\begin{array}{c}85.0 \pm 0.06 \\
\mathrm{p}<0.05\end{array}$ \\
\hline The number of platelets in the aggregates, $\%$ & $8.0 \pm 0.16$ & $8.2 \pm 0.09$ & $8.4 \pm 0.12$ & $8.6 \pm 0.08$ & $\begin{array}{l}9.2 \pm 0.11 \\
\mathrm{p}<0.05\end{array}$ \\
\hline $\begin{array}{l}\text { The number of small units per } 100 \text { free } \\
\text { platelets }\end{array}$ & $4.0 \pm 0.09$ & $4.4 \pm 0.07$ & $\begin{array}{l}4.9 \pm 0.03 \\
\mathrm{p}<0.05\end{array}$ & $\begin{array}{l}5.3 \pm 0.05 \\
\mathrm{p}<0.05\end{array}$ & $\begin{array}{l}6.0 \pm 0.09 \\
\mathrm{p}<0.01\end{array}$ \\
\hline $\begin{array}{l}\text { The number of medium and large units per } \\
100 \text { free platelets }\end{array}$ & $0.23 \pm 0.005$ & $0.26 \pm 0.006$ & $0.29 \pm 0.008$ & $\begin{array}{c}0.32 \pm 0.008 \\
\mathrm{p}<0.05\end{array}$ & $\begin{array}{c}0.36 \pm 0.007 \\
\mathrm{p}<0.01\end{array}$ \\
\hline
\end{tabular}

Note: $p$ - the reliability of changes in indicators during the dairy nutrition phase.

The intensity of AP recovery during a collagen-aspirin test, which provides an indirect assessment of the level of cyclooxygenase activity in the cytoplasm of platelets, increased from $75.0 \pm 0.08$ to $78.7 \pm 0.12 \%$. The level of
AT recovery during a collagen-imidazole test, which provides an indirect elucidation of platelet thromboxane synthetase activity level in platelets, also increased in the examined piglets during the observation from $64.2 \pm 0.07$ 
to $69.6 \pm 0.09 \%$. At the same time, the piglets during the milk-plant nutrition phase showed an increase in the amount of ADP in their platelets (by $12.5 \%$ ) and an intensification of the activity of its release from the granules (by $14.1 \%$ ).

In the blood of the piglets taken in the study, normal platelet levels were noted. In animals at the age of 21 days of life, AT in response to collagen occurred in $29.0 \pm 0.08 \mathrm{~s}$. This time gradually decreased to $24.5 \pm 0.05 \mathrm{~s}$ by the end of the observation (Table 1).

A similar acceleration of the AP process in piglets during the milk-vegetable nutrition phase occurred in response to $\mathrm{ADP}$ - by $15.2 \%, \mathrm{H}_{2} \mathrm{O}_{2}$ by $10.0 \%$ and ristomycin by $13.3 \%$. A little later, AP appeared in response to thrombin (by the end of the phase, AP appeared with it for $36.0 \pm 0.07 \mathrm{~s}$ ) and AP developed in response to adrenaline (by the end of the phase it was realized in $85.0 \pm 0.06 \mathrm{~s}$ ).

The increase in the number of platelet aggregates freely moving through the blood was found in animals of milk and vegetable nutrition.

Their number reached, on the 40th day of life, $6.0 \pm 0.09$ per 100 free blood plates and $0.36 \pm 0.007$ per 100 free blood plates. At the same time, an increase in the number of platelets involved in aggregation by $15.0 \%$ was observed in the examined piglets during the observation period.

\section{Discussion}

Increasing the volume of pig production is possible only with continued accumulation of knowledge on all aspects of piglet physiology $[11,12]$. This will help in the course of their application in practice to achieve greater vitality of animals and seriously accelerate the processes of their development and growth [13]. Of particular importance in this regard are systems that support homeostasis, including hemostasis $[14,15]$. This system includes physiologically significant platelets $[16,17]$.

It is believed that their activity during ontogenesis essentially determines the state of blood rheology in the capillaries and thus the level of metabolism activity in the tissues [18]. Due to the large physiological role of the level of platelet activity and the main mechanisms for their realization, it was necessary to evaluate their peculiarities during the change in dietary patterns in piglets.

Considering the obtained results, it is possible to assume that the ability of platelets to adhesion increases in piglets during the milk-plant nutrition phase. The basis of this is the increase in the content of von Willebrand factor in their blood, which acts as a cofactor for adhesion of platelets and an increase in the density of receptors to it on platelet membranes [19, 20]. Piglets say this by intensifying platelet aggregation using ristomycin [21].

This is due to the fact that it affects platelets as vascular subendothelial fibers [22]. During adhesion of von Willebrand factor, it binds to collagen, the second end to the platelet via the glycoprotein $\mathrm{Ib}$. This forms a chain that provides an adhesion process consisting of collagen-von Willebrand factor and glycoprotein Ib [23].

Found acceleration of AT in response to other inductors also showed an increase in the number of receptors on blood plates in piglets between 21 and 40 days of ontogenesis [24, 25]. It also spoke of the activation of the platelet mechanisms of antibodies in piglets at this age in response to strong and weak inducers of in vitro aggregation similar to those that implement the process of platelet aggregation in vivo [26].

A significant mechanism of its activation in piglets during the milk-plant nutrition phase is increased expression on the surface of their membranes to the fibrinogen receptor [27].

This is accompanied by an increase in the catalytic indices of their phospholipids, which caused an increase in the formation of active factor $\mathrm{X}$ and thrombin on them, which strongly stimulated the functioning of hemostasis in general [28].

\section{Conclusion}

Strengthening of platelet hemostasis in piglets that are in the dairy-plant nutrition phase is obviously associated with a pronounced increase in the functioning of the mechanisms of reception and post-receptor processes of participation in hemostasis in them. At this age in piglets, this leads to increased platelet adhesion, aggregation and secretion.

The growth of platelet activity in piglets during the milk-plant nutrition phase can be attributed from physiological points of view to the need to maintain microcirculation at the optimal level in their tissues, which, on the one hand, corresponds to piglet species, and, on the other hand, to environmental factors.

An increase in platelet activity in piglets during the milk-plant nutrition phase should be considered as one of the biologically significant adaptive reactions that can affect their growth and development.

\section{References}

1. H. Kulig, K. Żukowski, I. Kowalewska-Łuczak, P. Łakomy, Scd1Polymorphism and Breeding Value for Milk Production Traits in Cows, Bulgar. J. of Agricult. Sci., 22, 131-134 (2016)

2. G.N. Sushkevich, Abnormal hemostasis system and the principles of their correction (Sovetskaya Kuban, Krasnodar, 2010)

3. L.V. Korepanova, O.S. Starostina, S.D. Batanov, The Blood as an indicator of the interior features of the hybrid animals, Husbandry, 10, 26-28 (2015)

4. I.N. Medvedev, Physiological Activity Of The Blood Plates In Regularly Practicing Amateur Football Players, Res. J. of Pharmaceut., Biolog. and Chemical Sci., 9(6), 1161-1166 (2018)

5. L. Burnier, P. Fontana, B.R. Kwak, A. AngelilloScherrer, Cell-derived microparticles in haemostasis 
and vascular medicine, Thromb. Haemost, 101, 439-451 (2009)

6. A.A. Bikbulatova, Creating Psychological Comfort In Women Who Wear Corrective Clothing For A Long Time, Res. J. of Pharmaceut., Biolog. and Chemical Sci., 9(6), 1112-1121 (2018)

7. I.N. Medvedev, Functional Features Of Platelet Hemostasis In Athletes-Athletes 18-35 Years, Res. J. of Pharmaceut., Biolog. and Chemical Sci., 9(6), 1196-1201 (2018)

8. N.V. Vorobyeva, I.N. Medvedev, Functional activity of platelets in new-born calves of blackmarked breed, Bulgar. J. of Agricult. Sci., 25(3), 570-574 (2019)

9. I.N. Medvedev, Dynamics Of Functional Parameters Of Platelet Hemostasis In Young People With Hemodynamic And Metabolic Disorders On The Background Of Regular Physical Activity, Res. J. of Pharmaceut., Biolog. and Chemical Sci., 9(6), 1217-1222 (2018)

10. G.C. White, R. Rompietti, Platelet secretion: indiscriminately spewed forth or highly orchestrated? J. Thromb. Haemost, 5, 2009-2016 (2007)

11. I.N. Medvedev, Physiological Characteristics Of Platelet Activity In Young People Experiencing Moderate Exercise, Res. J. of Pharmaceut., Biolog. and Chemical Sci., 9(6), 1416-1421 (2018)

12. I.N. Medvedev, The Physiological State Of Intravascular Platelet Activity In Young Men Who Had High Normal Blood Pressure, Overweight Or A Combination Of Them And Started Regular Exercise, Res. J. of Pharmaceut., Biolog. and Chemical Sci., 9(6), 1438-1445 (2018)

13. I.N. Medvedev, Physiological Effects Of Physical Stress On Platelet Hemostasis In Young Individuals With High Normal Blood Pressure And Overweight, Res. J. of Pharmaceut., Biolog. and Chemical Sci., 9(6), 1466-1471 (2018)

14. I.N. Medvedev, Physiological Response Of Platelet Activity In Young People With High Normal Blood Pressure To Regular Exercise, Res. J. of Pharmaceut., Biolog. and Chemical Sci., 9(6), 1489-1494 (2018)

15. I.N. Medvedev, O.A. Danilenko, Complex correction of vascular hemostasis in patients with arterial hypertension, metabolic syndrome, and recent ocular vessel occlusion, Russ. J. of Cardiol., 4, 15-19 (2010)

16. A.S. Shitikova, Trombotsitopatii of congenital and acquired (St. Petersburg, 2008)

17. I.A. Skoryatina, I.N. Medvedev, Correction of aggregation level of basic regular blood elements in patients with hypertension and dyslipidemia receiving rosuvastatin and non-medicinal treatment,
Bali Med. J., 8(1), 194-200 (2019) DOI: 10.15562/bmj.v8i1.648

18. I.N. Medvedev, Physiological Response Of Intravascular Platelet Activity In Boys With High Normal Blood Pressure To Regular Physical Exercise, Res. J. of Pharmaceut., Biolog. and Chemical Sci., 9(6), 1244-1250 (2018)

19. E.M. Lenchenko, Yu.A. Vatnikov, E.V. Kulikov, D.A. Lozovoy, V.A. Gavrilov, L.A. Gnezdilova, V.N. Zimina, V.I. Kuznetsov, V.V. Annikov, I.N. Medvedev, A.V. Petryaeva, T.I. Glagoleva, Aspects of Salmonellosis pathogenesis using chicken models, Bali Med. J., 8(1), 206-210 (2019) DOI: 10.15562/bmj.v8i1.920

20. I.N. Medvedev, Functional Features Of Intravascular Platelet Activity In Adolescents With High Normal Blood Pressure, Overweight Or A Combination Of Them Against The Background Of Regular Physical Exertion, Res. J. of Pharmaceut., Biolog. and Chemical Sci., 9(6), 1258-1265 (2018)

21. A.A. Bikbulatova, Functional Features Of Microcirculatory Processes In Obese Women Against A Background Of Long Daily Wearing Of Corrective Clothing, Res. J. of Pharmaceut., Biolog. and Chemical Sci., 9(6), 785-793 (2018)

22. I.N. Medvedev, Vascular-platelet interaction in pregnant cows, Bulg. J. Agric. Sci, 23(2), 310-314 (2017)

23. Ju.L. Oshurkova, I.N. Medvedev, Functional Features Of Platelets In Newborn Calves Ayrshire Breed, Res. J. of Pharmaceut., Biolog. and Chemical Sci., 9(6), 313-318 (2018)

24. Ju.L. Oshurkova, I.N. Medvedev, Physiological Indicators Of Platelets In Ayrshire Calves During The Dairy Feeding Phase, Res. J. of Pharmaceut., Biolog. and Chemical Sci., 9(6), 171-176 (2018)

25. I.N. Medvedev, Physical Effect Of Feasible Physical Exertion On Platelet Activity In Overweight Young Men, Res. J. of Pharmaceut., Biolog. and Chemical Sci., 9(6), 1137-1142 (2018)

26. I.N. Medvedev, The Physiological Properties Of Platelets In People 18-35 Years Old, Trained In The Section Of General Physical Training, Res. J. of Pharmaceut., Biolog. and Chemical Sci., 9(6), 1277-1283 (2018)

27. I.N. Medvedev, Platelet Functions In The First Adulthood When Regularly Practiced In Adolescence In The Tennis Section, Res. J. of Pharmaceut., Biolog. and Chemical Sci., 9(6), 1180-1184 (2018)

28. N.V. Vorobyeva, I.N. Medvedev, Physiological Features Of Platelet Functioning In Calves Of Holstein Breed During The Newborn, Res. J. of Pharmaceut., Biolog. and Chemical Sci., 9(6), 129-135 (2018) 